\title{
Quantitative Indocyanine Green Fluorescence Imaging Used to Predict Anastomotic Leakage Focused on Rectal Stump During Laparoscopic Anterior Resection
}

\author{
Hiromitsu Iwamoto, MD, Kenji Matsuda, MD, Shinya Hayami, MD, Koichi Tamura, MD, Yasuyuki Mitani, MD, \\ Yuki Mizumoto, MD, Yuki Nakamura, MD, Daisuke Murakami, MD, Masaki Ueno, MD, Shozo Yokoyama, MD, \\ Tsukasa Hotta, MD, Katsunari Takifuji, MD, and Hiroki Yamaue, MD
}

\begin{abstract}
Background: Anastomotic leakage (AL) is arguably the most troublesome complication of anterior resection (AR). In recent years, however, indocyanine green (ICG) fluorescence imaging has been recently used to evaluate blood flow in the anastomosis site, and it has been suggested that AL may be predicted. We reported the effectiveness of predicting AL in colorectal cancer surgery by observing a quantitative laparoscopic ICG fluorescence imaging for the first time. The purpose of this study was to predict the risk of postoperative AL by quantitative laparoscopic ICG fluorescence imaging focused on the rectal stamp, which is one of the major causes of AL in AR, and to construct diverting stoma (DS) only in appropriate cases.

Methods: We studied the 25 patients who underwent elective laparoscopic AR for rectal cancer at our hospital between July 2016 and June 2017. Before enforcing double-stapling technique anastomosis, we injected ICG intravenously, and laparoscopically evaluated blood flow on the rectal stump. We analyzed quantitatively the relationship between various parameters and AL.

Results: Median T0, from when the ICG was injected intravenously and the ICG disappeared from the injection route to the rise of the histogram of intensity, in AL group was significantly longer than that in non-AL group $(P=.03)$. There were no other significant differences between AL and non-AL groups.

Conclusions: T0 was longer in patients with AL than in those without. If prolonged $\mathrm{T} 0$ can be recognized intraoperatively, it will be possible to construct DS for appropriate patients only.
\end{abstract}

Keywords: quantitative ICG fluorescence imaging, rectal stump, laparoscopic anterior resection, rectal cancer, diverting stoma

\section{Introduction}

A NASTOMOTIC LEAKAGE (AL) is arguably the most troublesome complication in rectal cancer surgery and raises the risk of local recurrence. ${ }^{1,2}$ It affects quality of life $^{3}$ and worsens prognosis for a long time after surgery. ${ }^{1,2}$ We therefore proactively construct diverting stoma (DS) in all cases of preoperative chemoradiotherapy (CRT) and cases considered to be high risk of AL. On the contrary, although temporary, the physical and mental burden is large when DS is used, and further surgery is eventually needed for stoma reversal. Furthermore, $16 \%$ of cases in which DS is used cannot receive stoma reversal, the patient must therefore live with stoma permanently. ${ }^{4}$
Studies have reported male sex, low anastomosis, preoperative chemoradiation, advanced tumor stage, one perioperative bleeding, and multiple firings of linear stapler as risk factors for AL after laparoscopic anterior resection (AR) with total mesorectal excision (TME) for rectal cancer. ${ }^{5-7}$ Blood flow disorder at the anastomosis site has also been reported to be a risk factor, but still there has been no method to evaluate blood flow of the anastomosis-site, and sufficient analysis could not be performed. In recent years, however, as a new method, indocyanine green (ICG) fluorescence angiography has been used to evaluate blood flow in the anastomosis site during colorectal cancer surgery. ${ }^{8}$ Furthermore, it was suggested that postoperative complications could be predicted

Second Department of Surgery, School of Medicine, Wakayama Medical University, Wakayama, Japan. 
by blood flow evaluation in the anastomosis site by ICG fluorescence imaging in colorectal cancer. ${ }^{9,10}$ We also reported the effectiveness of predicting AL in colorectal cancer surgery with a quantitative laparoscopic ICG fluorescence imaging for the first time. In that report, T0, the time from the administration of ICG to first observation of fluorescence, might be a useful parameter for prediction AL. ${ }^{11}$ On the contrary, there is a report that ICG fluorescence imaging to assess the blood flow on the anastomosis site had no impact on prediction of AL. ${ }^{12}$ If it is possible to evaluate the possibility of AL with high accuracy by intraoperative ICG fluorescence imaging, it will be possible for us to construct DS only in necessary cases.

In this study, we observed intestinal blood flow with laparoscopic quantitative ICG fluorescence imaging focused on the anal anastomosis site, rectal stump. It was thought to be closely related to the occurrence of AL in AR for rectal cancer. Also, a laparoscopic ICG fluorescence imaging was carried out before double-stapling technique (DST) anastomosis. Then we, quantitatively, analyzed the video of observation and evaluated the relationship between various parameters and AL.

\section{Materials and Methods}

\section{Patients}

Twenty-five patients were enrolled in this prospective analysis, who underwent elective laparoscopic AR with DST anastomosis for rectal cancer at Wakayama Medical University Hospital (WMUH) between July 2016 and June 2017. This study protocol was approved by the Institutional Review Board of Wakayama Medical University, Japan, and was registered in UMIN Clinical Trials Registry as UMIN000022876. Written informed consent was obtained from all patients for the use of their clinical data.

\section{Surgical methods}

All procedures were performed by well-experienced, board-certified laparoscopic colorectal surgeons at WMUH. All patients underwent standard bowel preparation and antibiotic administration. The procedure of laparoscopic colon surgery is standardized in our department, but dissection of the inferior mesenteric artery was made according to the stage of the patient or state of the blood vessel. Mobilization of the splenic flexure was performed only when unnecessary tension was applied to the anastomosis site. After mobilization of the left colon, TME was performed in middle or lower rectal cancer, while those with upper rectal cancer received term-specific mesorectal excision. A sufficient margin was secured on the anal side of the tumor, a cutting part was set and clamped in place and the anal end of the rectum was washed with saline. We then resected the rectum using a laparoscopic linear stapler. Before enforcing DST anastomosis, we injected ICG (7.5 mg) (Diagnogreen; Daiichi Sankyo, Tokyo, Japan) intravenously and evaluated the blood
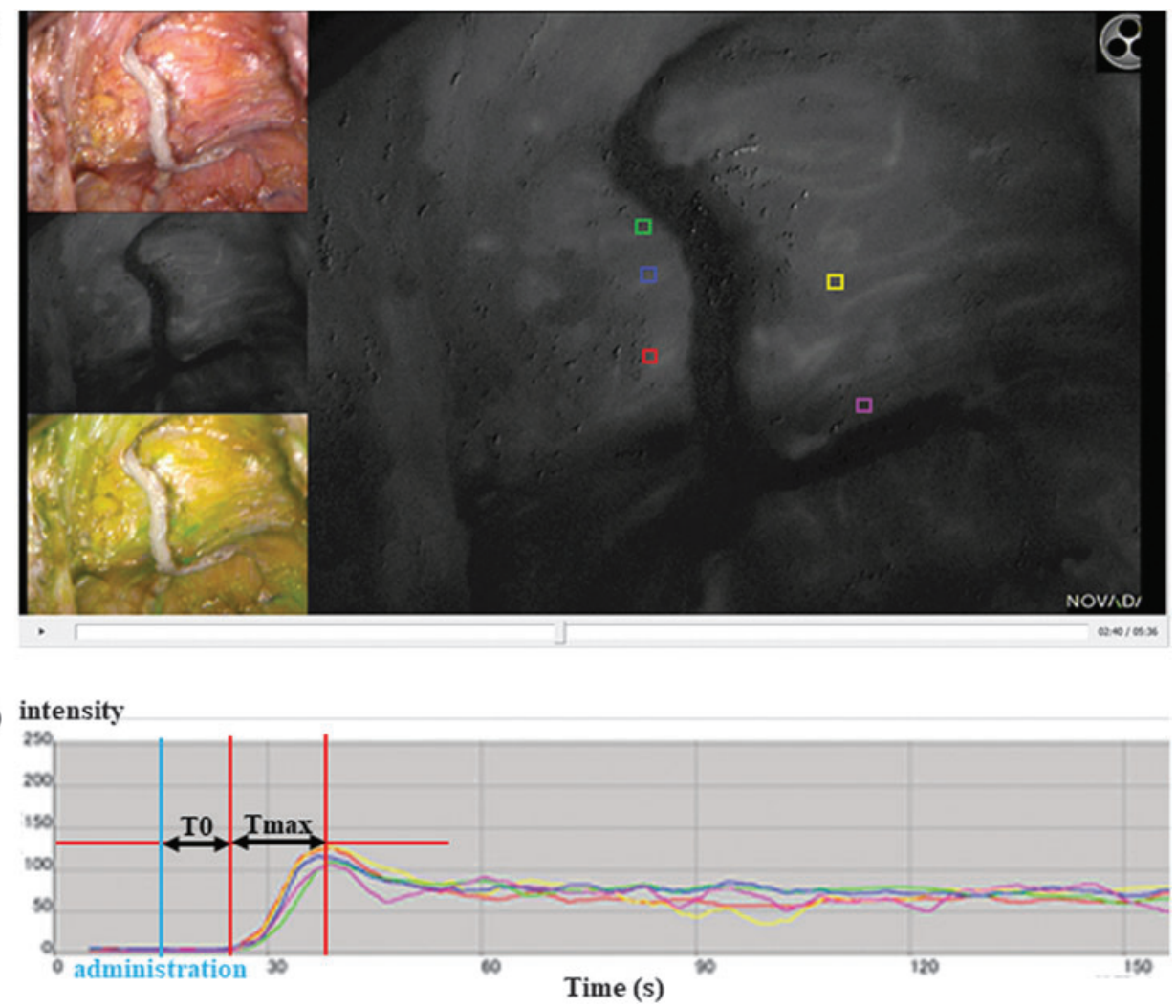

FIG. 1. Visualization of blood flow of anal anastomosis site by laparoscopic ICG fluorescence imaging in Image analyzer ROIs system ${ }^{\circledR}$. (a) Blood flow of anal anastomosis site observed by PINPOINT Endoscopic Fluorescence Imaging System ${ }^{\circledR}$ and analyzed by Image analyzer ROIs system (b) the methods of analysis for T0 and Tmax with Image analyzer ROIs system. The color of each curve matches that of the ROIs in (a). The curve shows the intensity in each ROI over time. ICG, indocyanine green. 
flow focused only on the rectal stump by laparoscope with ICG mode. The laparoscope was fixed $5 \mathrm{~cm}$ apart from the anal anastomosis site for 5 minutes. Finally, end to end DST anastomosis with a circular stapler was completed intracorporeally. The use of pelvic drain and transanal drain was according to surgeon's preference, DS was used in cases of lower rectal cancer and in all patients receiving preoperative CRT. After operation, we analyzed the video of observation and evaluated the relationship between various parameters and AL using Image analyzer ROIs system ${ }^{\circledR}$ (Hamamatsu Photonics K.K., Hamamatsu, Japan). We set five appropriate measuring points (ROI) on microarteries near the stapler line on the rectal stump. "T0" was the time from when the ICG was injected intravenously and the ICG disappeared from the injection route to the rise of the histogram of intensity. "Tmax" was the time from when the ICG disappeared from the injection route to the time when the average luminance was at maximum (Fig. 1).

\section{Definition of clinical $A L$}

$\mathrm{AL}$ was defined as any fissure of the anastomosis that was confirmed by radiographic examination (e.g., extravasation of endoluminally administered water-soluble contrast enema, abscess at level of anastomosis, and fluid/air bubbles around the anastomosis). ${ }^{13} \mathrm{We}$ therefore included both symptomatic (grade B, C) and asymptomatic (grade A) AL in the analysis.

\section{Statistical analysis}

Values are expressed as means \pm SD. $\chi^{2}$-test was used for comparison and analysis of categorical variables. All analyses were two sided, and a $P<.05$ was considered statistically significant. All statistical analyses were conducted with the JMP pro software, version 13.0.0 (SAS Institute, Inc., NC).

\section{Results}

\section{Patient characteristics}

A total of 25 patients with rectal cancers were analyzed. Patient characteristics are listed in Table 1. The locations of tumors were upper rectum 5 (20\%), middle rectum $8(32 \%)$, and lower rectum $12(48 \%)$. In terms of the TNM classification, $1(4 \%)$ patient was Stage 0, 7 (28\%) patients were Stage I, $9(36 \%)$ patients were Stage II, 6 (24\%) patients were Stage III, and $2(8 \%)$ patients were Stage IV. Five patients $(20 \%)$ had a history of diabetes mellitus (DM), $13(52 \%)$ patients had a history of hypertension (HT), and 3 (12\%) patients had a history of ischemic heart disease (IHD).

We classified all patients into two groups: AL group (International Study Group of Rectal Cancer Grade $A=2$ patients, $\mathrm{B}=3$ patients, and $\mathrm{C}=1$ patient) and the non-AL group $(n=19,76 \%)$. No significant differences were found between the two groups in terms of sex, age, BMI, location of tumors, UICC-TNM stage or history of DM, HT, or IHD (Table 1).

\section{Perioperative status}

In terms of operative procedure, 6 patients underwent high anterior resection (HAR) and 19 patients underwent low anterior resection. There was no cases of conversion to an open procedure. The median operative time $( \pm \mathrm{SD})$ of all patients was 259 126 minutes (158-762 minutes). Median
Table 1. Patient and Clinical Characteristics

\begin{tabular}{|c|c|c|c|c|}
\hline & $\mathrm{n}$ & $\begin{array}{c}\text { AL group } \\
(\mathrm{n}=6)\end{array}$ & $\begin{array}{l}\text { Non-AL group } \\
(\mathrm{n}=19)\end{array}$ & $\mathrm{P}$ \\
\hline \multicolumn{5}{|l|}{ Sex } \\
\hline Male & 17 & $4(67 \%)$ & $13(68 \%)$ & \multirow[t]{2}{*}{.94} \\
\hline Female & 8 & $2(33 \%)$ & $6(32 \%)$ & \\
\hline Age (years) & & $65.5 \pm 74.5$ & $69.0 \pm 9.7$ & .59 \\
\hline BMI & & $22.0 \pm 3.5$ & $21.4 \pm 3.6$ & .80 \\
\hline \multicolumn{5}{|c|}{ Location of tumors } \\
\hline Upper & 5 & $1(17 \%)$ & $4(21 \%)$ & \multirow[t]{3}{*}{.55} \\
\hline Middle & 8 & $1(17 \%)$ & $7(37 \%)$ & \\
\hline Lower & 12 & $4(66 \%)$ & $8(42 \%)$ & \\
\hline \multicolumn{5}{|l|}{ TNM stage } \\
\hline 0 & 1 & $1(17 \%)$ & $0(0 \%)$ & \multirow[t]{5}{*}{.51} \\
\hline $\mathrm{I}$ & 7 & $2(33 \%)$ & $5(26 \%)$ & \\
\hline II & 9 & $2(33 \%)$ & $7(37 \%)$ & \\
\hline III & 6 & $1(17 \%)$ & $5(26 \%)$ & \\
\hline IV & 2 & $0(0 \%)$ & $2(11 \%)$ & \\
\hline \multicolumn{5}{|l|}{$\mathrm{DM}$} \\
\hline+ & 5 & $1(17 \%)$ & $4(21 \%)$ & \multirow[t]{2}{*}{.12} \\
\hline- & 20 & $5(83 \%)$ & $15(79 \%)$ & \\
\hline \multicolumn{5}{|l|}{ HT } \\
\hline+ & 13 & $5(83 \%)$ & $8(42 \%)$ & \multirow[t]{2}{*}{.08} \\
\hline- & 12 & $1(17 \%)$ & $11(58 \%)$ & \\
\hline \multicolumn{5}{|l|}{ IHD } \\
\hline+ & 3 & $2(33 \%)$ & $1(5 \%)$ & \multirow[t]{2}{*}{.07} \\
\hline- & 22 & $4(67 \%)$ & $18(95 \%)$ & \\
\hline
\end{tabular}

$\mathrm{AL}$, anastomotic leakage; BMI, body mass index; DM, diadetes mellitus; HT, hypertension; IHD, ischemic heart disease; TNM, tumor node metastasis.

intraoperative blood loss $( \pm \mathrm{SD})$ of all patients was $20 \pm 107 \mathrm{~mL}(5-400 \mathrm{~mL})$. There were no significant differences between the two groups in terms of operative time, intraoperative blood loss, operative procedure, DS, transanal drain, number of staplers, lateral lymph node dissection, and/or preoperative CRT (Table 2).

\section{Quantitative analysis of time-fluorescence intensity curve of TO and Tmax}

Median T0 in AL group was 37.5 \pm 17.1 seconds, significantly longer than $11.0 \pm 13.1$ seconds in non-AL group $(P=.03)$. On the contrary, Tmax was $11.5 \pm 7.3$ seconds in the AL group, and there was no significant difference $(P=.85)$ compared with $12.0 \pm 9.3$ seconds in the non-AL group (Table 3).

\section{Discussion}

The incidence of symptomatic AL after AR has been reported variously between $6.3 \%$ and $13.2 \% .^{2,5,6,14-16}$ This proportion has gradually declined with the progress of surgical procedures and equipment, ${ }^{14,17}$ but it is still far from $0 \%$. In this study, the incidence of AL was high as $24 \%$, but symptomatic $\mathrm{AL}$ (grade $\mathrm{B}+\mathrm{C}$ ) is 4 cases $(16 \%$ ), and it is considered to be equivalent to the reports to date. If we could intraoperatively define patients with symptomatic AL (grade C), which requires emergency surgery, we could adequately reduce emergency surgery by construction of DS. ${ }^{16}$ Until now, however, there was no suitable parameter for extraction of cases requiring DS. 
Table 2. Operative Procedure

\begin{tabular}{|c|c|c|c|c|}
\hline & $\mathrm{n}$ & $\begin{array}{l}\text { AL group } \\
(\mathrm{n}=6)\end{array}$ & $\begin{array}{l}\text { Non-AL group } \\
(\mathrm{n}=19)\end{array}$ & $\mathrm{P}$ \\
\hline Time (minutes) & & $285.5 \pm 58.7$ & $259 \pm 128.6$ & .61 \\
\hline Blood loss $(\mathrm{mL})$ & & $17.5 \pm 7.5$ & $20 \pm 110.8$ & .20 \\
\hline \multicolumn{5}{|l|}{ Procedure } \\
\hline HAR & 6 & $1(17 \%)$ & $5(26 \%)$ & \multirow[t]{2}{*}{.63} \\
\hline LAR & 19 & $5(83 \%)$ & $14(74 \%)$ & \\
\hline \multicolumn{5}{|l|}{ DS } \\
\hline+ & 15 & $5(83 \%)$ & $10(53 \%)$ & \multirow[t]{2}{*}{.12} \\
\hline- & 10 & $1(17 \%)$ & $9(47 \%)$ & \\
\hline \multicolumn{5}{|l|}{ Abdominal drain } \\
\hline+ & 10 & $2(33 \%)$ & $8(42 \%)$ & \multirow[t]{2}{*}{.70} \\
\hline- & 15 & $4(67 \%)$ & $11(58 \%)$ & \\
\hline \multicolumn{5}{|l|}{ Transanal drain } \\
\hline+ & 12 & $3(50 \%)$ & $9(47 \%)$ & \multirow{2}{*}{.91} \\
\hline- & 13 & $3(50 \%)$ & $10(53 \%)$ & \\
\hline \multicolumn{5}{|l|}{ Number of stapler } \\
\hline 1 & 9 & $2(33 \%)$ & $7(37 \%)$ & \multirow[t]{3}{*}{.95} \\
\hline 2 & 15 & $4(67 \%)$ & $11(58 \%)$ & \\
\hline 3 & 1 & $0(\%)$ & $1(5 \%)$ & \\
\hline \multicolumn{5}{|l|}{ LLND } \\
\hline+ & 2 & $0(0 \%)$ & $2(11 \%)$ & \multirow[t]{2}{*}{.41} \\
\hline- & 23 & $6(100 \%)$ & $17(89 \%)$ & \\
\hline \multicolumn{5}{|l|}{ CRT } \\
\hline+ & 6 & $1(17 \%)$ & $5(26 \%)$ & \multirow[t]{2}{*}{.63} \\
\hline- & 19 & $5(83 \%)$ & $14(74 \%)$ & \\
\hline
\end{tabular}

AL, anastomotic leakage; CRT, chemoradiotherapy; DS, diverting stoma; HAR, high anterior resection; LAR, low anterior resection; LLND, lateral lymph node dissection.

The most novelty of this study is that quantitative observation of the blood flow at the anastomosis site was performed laparoscopy focusing only on the anal side, rectal stump. The lack of blood supply in the anal side may be the cause of AL. We sometimes experience dehiscence at the stapler line. Blood flow on the rectal stump is often derived from the middle rectal artery, damage to the middle rectal artery may decrease blood flow to the remnant rectum. Multiple firings of linear stapler reportedly increases AL because of increase on the staple site..$^{5-7,18}$ Blood flow evaluation has been carried out by laser-Doppler flowmetry technique or angiography and reports to date state that reduction in blood flow at the anal anastomosis site is a cause of AL. ${ }^{19-21}$ In this study, quantitative laparoscopic ICG fluorescence angiography was introduced as a new method of blood flow evaluation, and correlation between blood flow in the anal anastomosis site and AL was examined. As a result, it was found that T0, from administration of ICG to the first observation of fluorescence, was significantly prolonged in

Table 3. Quantitative Analysis of Time-Fluorescence Intensity Curve OF T0 AND TMAX

\begin{tabular}{lccc}
\hline & AL group $(\mathrm{n}=6)$ & Non-AL group $(\mathrm{n}=19)$ & $\mathrm{P}$ \\
\hline T0 & $37.5 \pm 17.1$ & $11 \pm 13.1$ & $.03^{\mathrm{a}}$ \\
Tmax & $11.5 \pm 7.3$ & $12 \pm 9.3$ & .85 \\
\hline
\end{tabular}

\footnotetext{
${ }^{\mathrm{a}} \mathrm{AL}$ group is significantly longer than non-AL group.
}

$\mathrm{AL}$, anastomotic leakage. the AL group. No reports have yet performed quantitate analysis by using laparoscopic ICG imaging of the blood fow in the anastomosis site, including a rectal stump, but there is a report that the reduction of the blood flow of small arteries during operation is a risk factor for $\mathrm{AL}{ }^{21}$ It seems that the prolongation of $\mathrm{T} 0$ is indicative of a decrease in the blood flow of these small arteries, and it is therefore considered to be significantly prolonged in the AL group.

\section{Conclusion}

In quantitative laparoscopic ICG fluorescence image, T0 was longer in patients with AL than in those without. Therfore, if prolonged T0 can be recognized intraoperatively, DS can be constructed only for patients who require it.

\section{Disclosure Statement}

No competing financial interests exist.

\section{Funding Information}

No funding was received for this article.

\section{References}

1. Mirnezami A, Mirnezami R, Chandrakumaran K, Sasapu $\mathrm{K}$, Sagar P, Finan P. Increased local recurrence and reduced survival from colorectal cancer following anastomotic leak: Systematic review and meta-analysis. Ann Surg 2011;253: 890-899.

2. den Dulk M, Marijnen CA, Collette L, Putter H, Påhlman L, Folkesson J, Bosset JF, Rödel C, Bujko K, van de Velde CJ. Multicentre analysis of oncological and survival outcomes following anastomotic leakage after rectal cancer surgery. Br J Surg 2009;96:1066-1075.

3. Mongin C, Maggiori L, Agostini J, Ferron M, Panis Y. Does anastomotic leakage impair functional results and quality of life after laparoscopic sphincter-saving total mesorectal excision for rectal cancer? A case-matched study. Int J Colorectal Dis 2014;29:459-467.

4. Haksal M, Okkabaz N, Atici AE, Civil O, Ozdenkaya Y, Erdemir A, Aksakal N, Oncel M. Fortune of temporary ileostomies in patients treated with laparoscopic low anterior resection for rectal cancer. Ann Surg Treat Res 2017; 92:35-41.

5. Kawada K, Hasegawa S, Hida K, Hirai K, Okoshi K, Nomura A, Kawamura J, Nagayama S, Sakai Y. Risk factors for anastomotic leakage after laparoscopic low anterior resection with DST anastomosis. Surg Endosc 2014;28: 2988-2995.

6. Park JS, Choi GS, Kim SH, Kim HR, Kim NK, Lee KY, Kang SB, Kim JY, Lee KY, Kim BC, Bae BN, Son GM, Lee SI, Kang H. Multicenter analysis of risk factors for anastomotic leakage after laparoscopic rectal cancer excision: The Korean laparoscopic colorectal surgery study group. Ann Surg 2013;257:665-671.

7. Yamamoto S, Fujita S, Akasu T, Inada R, Moriya Y, Yamamoto S. Risk factors for anastomotic leakage after laparoscopic surgery for rectal cancer using a stapling technique. Surg Laparosc Endosc Percutan Tech 2012;22: 239-243.

8. Boni L, David G, Dionigi G, Rausei S, Cassinotti E, Fingerhut A. Indocyanine green-enhanced fluorescence to assess bowel perfusion during laparoscopic colorectal resection. Surg Endosc 2016;30:2736-2742. 
9. Boni L, Fingerhut A, Marzorati A, Rausei S, Dionigi G, Cassinotti E. Indocyanine green fluorescence angiography during laparoscopic low anterior resection: Results of a case-matched study. Surg Endosc 2017;31:1836-1840.

10. Kawada K, Hasegawa S, Wada T, Takahashi R, Hisamori S, Hida K, Sakai Y. Evaluation of intestinal perfusion by ICG fluorescence imaging in laparoscopic colorectal surgery with DST anastomosis. Surg Endosc 2017;31:1061-1069.

11. Hayami S, Matsuda K, Iwamoto H, Ueno M, Kawai M, Hirono S, Okada K, Miyazawa M, Tamura K, Mitani Y, Kitahata Y, Mizumoto Y, Yamaue H. Visualization and quantification of anastomotic perfusion in colorectal surgery using near-infrared fluorescence. Tech Coloproctol 2019;23:973-980.

12. Kin C, Vo H, Welton L, Welton M. Equivocal effect of intraoperative fluorescence angiography on colorectal anastomotic leaks. Dis Colon Rectum 2015;58:582-587.

13. Rahbari NN, Weitz J, Hohenberger W, Heald RJ, Moran B, Ulrich A, Holm T, Wong WD, Tiret E, Moriya Y, Laurberg S, den Dulk M, van de Velde C, Büchler MW. Definition and grading of anastomotic leakage following anterior resection of the rectum: A proposal by the International Study Group of Rectal Cancer. Surgery 2010;147:339-351.

14. Matsuda K, Hotta T, Takifuji K, Yokoyama S, Oku Y, Watanabe T, Mitani Y, Ieda J, Mizumoto Y, Yamaue H. Randomized clinical trial of defaecatory function after anterior resection for rectal cancer with high versus low ligation of the inferior mesenteric artery. Br J Surg 2015; 102:501-508.

15. Frouws MA, Snijders HS, Malm SH, Liefers GJ, Van de Velde CJH, Neijenhuis PA, Kroon HM. Clinical relevance of a grading system for anastomotic leakage after low anterior resection: Analysis from a national Cohort Database. Dis Colon Rectum 2017;60:706-713.

16. Shiomi A, Ito M, Maeda K, Kinugasa Y, Ota M, Yamaue H, Shiozawa M, Horie H, Kuriu Y, Saito N. Effects of a diverting stoma on symptomatic anastomotic leakage after low anterior resection for rectal cancer: A propensity score matching analysis of 1,014 consecutive patients. J Am Coll Surg 2015;220:186-194.

17. Hotta T, Takifuji K, Yokoyama S, Matsuda K, Ieda J, Watanabe T, Tamura K, Mitani Y, Iwamoto H, Takei Y, Mizumoto Y, Tsumura A, Deguchi M, Yamaue H. Horizontal rectal transection using an endolinear stapler for laparoscopic low anterior resection. Tech Coloproctol 2017;21: 311-313.

18. Lee $\mathrm{S}$, Ahn B, Lee $\mathrm{S}$. The relationship between the number of intersections of staple lines and anastomotic leakage after the use of a double stapling technique in Laparoscopic colorectal surgery. Surg Laparosc Endosc Percutan Tech 2017;27:273-281.

19. Rutegård $\mathrm{M}$, Hassmén $\mathrm{N}$, Hemmingsson $\mathrm{O}$, Haapamäki MM, Matthiessen $\mathrm{P}$, Rutegård $\mathrm{J}$. Anterior resection for rectal cancer and visceral blood flow: An explorative study. Scand J Surg 2016;105:78-83.

20. Vignali A, Gianotti L, Braga M, Radaelli G, Malvezzi L, Di Carlo V. Altered microperfusion at the rectal stump is predictive for rectal anastomotic leak. Dis Colon Rectum 2000;43:76-82.

21. Allison AS, Bloor C, Faux W, Arumugam P, Widdison A, Lloyd-Davies E, Maskell G. The angiographic anatomy of the small arteries and their collaterals in colorectal resections: some insights into anastomotic perfusion. Ann Surg 2010;251:1092-1097.

Address correspondence to: Hiroki Yamaue, MD Second Department of Surgery School of Medicine Wakayama Medical University 811-1 Kimiidera Wakayama 641-8510 Japan

E-mail: yamaue-h@wakayama-med.ac.jp 